\title{
FORECASTING THE AVERAGE TEMPERATURE RISE IN BANGLADESH: A
} TIME SERIES ANALYSIS

\author{
Sneha Paul ${ }^{1 *}$ and Shuvendu Roy ${ }^{2}$ \\ ${ }^{1}$ Dept. of Urban and Regional Planning, Khulna University of Engineering \& Technology, Khulna-9203 \\ ${ }^{2}$ Dept. of Computer Science and Engineering, Khulna University of Engineering \& Technology, Khulna-9203 \\ Received: 03 April 2020 \\ Accepted: 15 May 2020
}

\begin{abstract}
Global warming has caused a significant increment in surface temperature around the world, including Bangladesh. In this study, the temperature data of Bangladesh over the past 100 years has been analyzed to see the temperature increment pattern. It has been seen that the average temperature has risen by $1^{0} \mathrm{C}$ over the last century. Using daily average temperature data of Bangladesh, machine learning-based time series forecasting model has been developed to predict the future temperature of Bangladesh. The model can predict the minimum, maximum, and average temperatures of any year in the future. This has been treated as a regression problem and Linear, Polynomial, and Support Vector Regression have been proposed to build the prediction model. The proposed model has a mean square error of $0.0047^{\circ} \mathrm{C}$ which is a good margin for such a model. Using the model, the average temperature of Bangladesh is predicted over the next hundred years.
\end{abstract}

Keywords: Global warming; Climate Change; Average Temperature rise; Prediction; Bangladesh.

\section{INTRODUCTION}

Global warming indicates the rise of the mean temperature of the Earth's surface. Although global warming and climate change are often used as a synonym, global warming is the effect and climate change is the reason (Venkataramanan \& Smitha, 2011). Over the last 100 years, the average air temperature near the Earth's surface has risen by a little less than 1 degree Celsius (Orr, 2007). The rise of the surface temperature of Earth plays a vital role in global warming. Other factors affecting global warming are the increase of $\mathrm{CO}_{2}$ in the atmosphere, burning of fossil fuel, deforestation, extraction of greenhouse gases from the air conditioner, refrigerators, etc. These pollutants absorb and trap the sunlight and solar radiation heating the Earth's surface, as such the average temperature of earth increases. Climatic phenomena have enhanced due to global warming. Sea is getting warmer along with sea-level rise (Lindzen, 2008). Oceans have warmed and a strong decline has occurred in Arctic sea ice. Both natural causes and man-made activities are responsible for global warming. Among the various natural causes, most influential are volcanic eruptions and internal fluctuations in the climate system. But human activities such as: cutting off trees, burning fossil fuels, using motorized vehicles, refrigerators, air conditioners ejecting $\mathrm{CO}_{2}$ and greenhouse gasses, etc. are major responsible for global warming.

As human activities are major suspected responsible for climate change and global warming, Intergovernmental Panel on Climate Change (IPCC) was established by the World Meteorological Organization and the United Nations Environment Programme to investigate the factors working behind climate change and global warming (UNFCCC, 2005). For producing the assessment of IPCC, hundreds of scientists around the world are working to develop advanced mathematical modeling that will be able to predict future changes, monitor historical and present variation in climate (Houghton, 2004). As more research is doing on climate change, the occurrence of global warming and its impacts are becoming more and more absolute and clear to the scientists. According to the Fourth Assessment Report of the IPCC, since the mid-20th century the rise in greenhouse gas concentrations is liable to increase in global average temperature. According to the observation of the past 50 years, the external forces (forces that are outside human influence) are also responsible for the widespread warming of the atmosphere and ocean, together with ice mass loss (Alley, 2007).

Global warming affects various aspects of different regions in the world with different geographical contexts. According to Tol (2006), countries with higher latitudes such as Canada, Russia, and Scandinavia, climate change results in the rise of temperature by 2 or $3^{\circ} \mathrm{C}$ which may lead to net advantages, for example, increased agricultural outturn, decreased winter fatality, decreased heating necessity, and a probable uplift to tourism (Zholudeva, 2019). Along with the positive factors, negative factors also grasp these regions. For example, rapid growth of rates of warming; damage of infrastructure, human health, local establishments, and biodiversity (Shahzad, 2015). Indirect effects of global warming are seen such as an increase in mortality rate due to hot weather among the old and poor urban dwellers (UNFCCC, 2005). For example, in Shanghai, China will face a rise in the diurnal average mortality (35-63 extra additional deaths per day) due to high average temperature and humidity, while French has faced 15,000 additional deaths due to heat wave in summer 2003 (Tol, 2006). Bangladesh is situated geographically in the tropical region (Islam, 2004). Due to its geographical location, 
natural disaster and climate change are general phenomena (Daily Star, 2019). The geographical features are responsible for making this country vulnerable to natural disasters. The challenges faced by this country due to climate change are elevated due to the enormous level of poverty (ICDDR B, 2019). According to the research report of Action Aid, Bangladesh ranked fifth most vulnerable country to climate change and hunger.

In the World Risk Index 2011, Bangladesh ranked sixth among the most vulnerable countries to natural disasters, while second among the Asian countries (Daily Star, 2019). Bangladesh is a low energy-consuming country. It contributes only $0.3 \%$ of the amount of emission which contributes to global warming. But the effects of global warming make Bangladesh one of the worst victims (Elahi, 2015). The average temperature of 30 years in Bangladesh is $27.5^{\circ} \mathrm{C}$ and the average summer temperature in monsoon is relatively higher than the summer (Mahmood, 2012). Researchers have done various studies and developed mathematical models to predict average surface temperature which portrays global warming and climate change. Two observational analysis combining land surface temperature analysis and sea surface temperature analysis is done and a Canadian Global Climate Model (CanCM4) established. This model incorporates observed anthropogenic concentrations of greenhouse gases, emissions of aerosol precursors, and naturally occurring forcing to the year 2005 (Fyfe, 2011). To predict twentieth-century global average temperature changes, analysis is made on three different climate models with very diverse sensitivities and aerosol forcing (Al, 2006). A real-time multi-model is also used to see the decadal change in climate (Smith, 2012).

According to the instrumental record of global surface temperature which began in 1850, eleven years among the last twelve years (1995-2006) has been ranked as the hottest years (Alley et al., 2007). Further evidence has also been seen that global warming is deteriorating weather and the environment in several ways causing various problems: between the years 1993 and 2003, sea level has been elevated due to melting polar ice caps at a rate of $3.1 \mathrm{~mm}$ every year (Pender, 2008). Furthermore, droughts have been increased in some areas, and rain has become heavier in others due to the change in patterns of rainfall. According to the Fourth Assessment Report of IPCC, it has been expected that global warming will be increased at a rate of $0.2^{\circ} \mathrm{C}$ per decade from the next twenty years. It has been predicted that the rise of average global temperature will be between a $1.8^{\circ} \mathrm{C}$ and $4^{\circ} \mathrm{C}$ by the year 2100 (Lindzen, 2008). Although the magnitude of temperature rise solely depends on the actions that are taken presently to stop greenhouse gas pollution. However, if the present trends of pollution are not being changed, a $1-3^{\circ} \mathrm{C}$ rise of temperature is being expected in average global temperature during the next fifty years (Tol, 2006).

In this study, the past 100 years' temperature rise data of Bangladesh has been analyzed to find out the temperature rise trend for this region. Three models: linear regression model, polynomial regression model, support vector model (SVR) are developed to predict the average temperature rise in Bangladesh for the next 100 years.

\section{METHODOLOGY}

This section describes the methodologies used to build the prediction model to forecast the temperature of Bangladesh in the future. The problem is treated as a regression task and experimented with different algorithms to build the best model for this application. Following algorithm is used in the experiments:

(a) Linear Regression

(b) Polynomial Regression

(c) Support Vector Regression (SVR)

\subsection{Linear Regression}

The linear regression model is implemented as a baseline for predicting the temperature in the future. In this study, the input variable is the year in which a single number and the output variable is the temperature, which is a real number. Representing the input variable year as $\mathrm{X}$ and the predicted variable temperature as $\mathrm{Y}$, the linear regression is expressed as:

$$
Y=\beta_{0}+\beta_{1} X
$$

Here, $\beta_{0}$ and $\beta_{1}$ are the coefficients of the linear regression model. The model learns by minimizing the least square errors. The model is never perfect and there is a difference between the predicted value and the actual value. The error is represented as:

$$
e_{i}=y_{i}-\hat{y}_{i}
$$

Least square error is squared of the error. The squared error is considered instead of the raw error because the prediction from the model can be above or below the true value, which will cause a positive and negative error which might cancel out when a train in batch. Also, the square will penalize the large difference more than that of small differences. So, the model will try to make small mistakes rather than a huge difference between the actual value and the prediction. 
Figure 1 explains the linear fit of a dataset. The red dots are the data points and the blue line is the linear fit line to model the dataset. The coefficients of the linear regression model can be calculated with the following equations:

$$
\begin{gathered}
\beta_{1}=\frac{\sum_{i=1}^{n}\left(x_{i}-\bar{x}\right)\left(y_{i}-\bar{y}\right)}{\sum_{i=1}^{n}\left(x_{i}-\bar{x}\right)^{2}} \\
\beta_{0}=\bar{y}-\beta_{1} \bar{x}
\end{gathered}
$$

Experiments are done with different types of predictions with all the models of consideration. We have modeled the mean, minimum, and maximum temperature of every year. As the temperature of consecutive years does not differ too much, we have also experimented with a 10-year average temperature model.

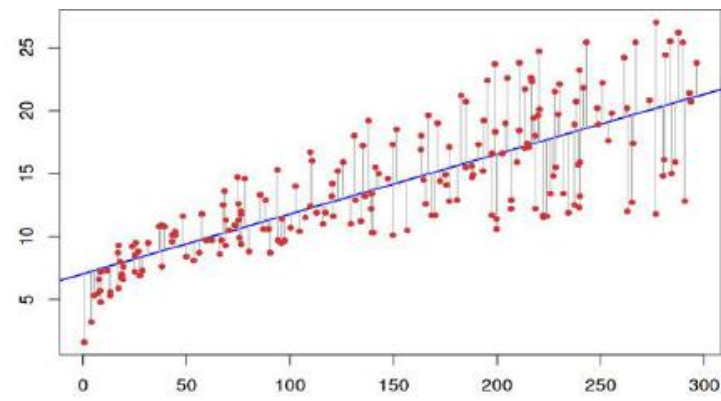

Figure 1: Linear regression fit to a dataset

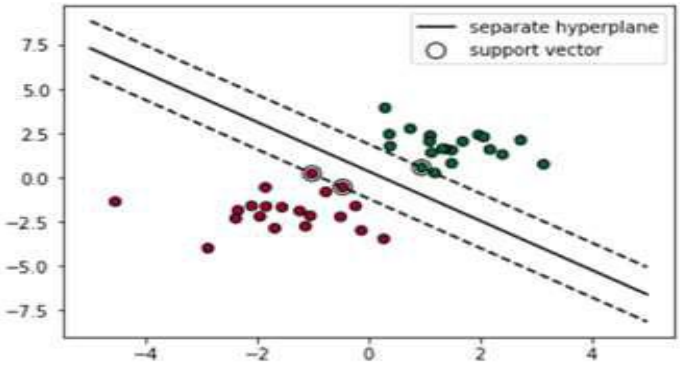

Figure 3: Support Vector Machine

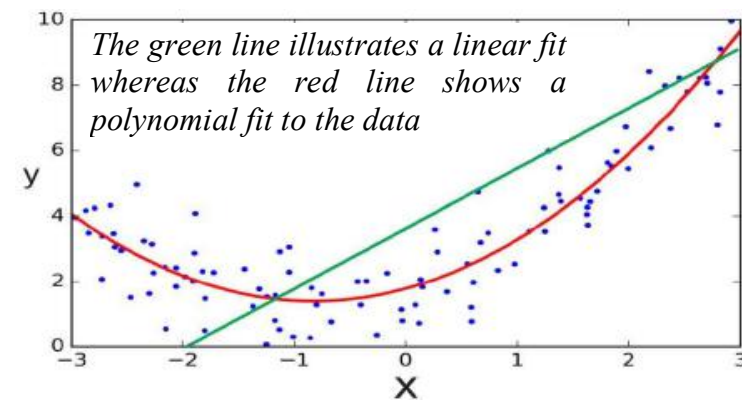

Figure 2: Comparison of Linear Regression and Polynomial Regressions.

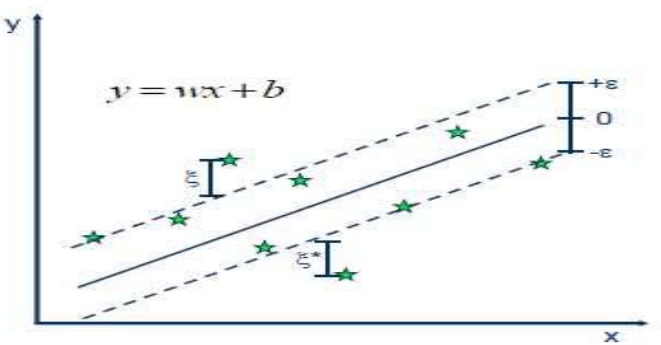

Figure 4: Support Vector Regression model

\subsection{Polynomial Regression}

Polynomial regression comes into play when the data points are not correlated, which means there does not exist a linear relationship between the independent variable and the predicted variable. Polynomial regression (Ruppert, 1997) appeared in many other climate researches in the past. Polynomial regression considers the higher orders in the data and tries to fit the line in multidimensional space. The formula for Polynomial regression of order $\mathrm{n}$ is represented as:

$$
Y=\beta_{0}+\beta_{1} X+\beta_{2} X^{2}+\beta_{3} X^{3}+\cdots+\beta_{n} X^{n}
$$

The polynomial regression provides the best approximate fit to the data. It fits a wide range of curvature in multidimensional space. Figure 3 illustrates a degree-2 polynomial fit to a data compared with the linear regression fit.

Figure 2 illustrates that there is no linear line that could fit the data properly. The polynomial regression fits a curved line to the data that most correctly fit the data. The temperature data is not linear either, so the polynomial regression with a higher degree has experimented in this study.

\subsection{Support Vector Regression (SVR)}

Support Vector Regression (SVR) (Drucker, 1997) is built on the concept of the support vector machine. The concept is extended from the support vector classifier, which is a popular classification problem. The concept of a support vector machine is to find the best line that separates the different features in maximum distance. For linearly separable problem can be easily modeled with a linear model. Figure 3 and 4 illustrates the concept of the support vector machine.

In Figure 3, a separator hyperplane constructed with the support vectors shown with the red and green circle. These are the vector closest to the other side and the separator hyperplane is contracted to separate these points. 
The SVR shown in Figure 4 uses the same concept, which is used by the classification model, with only some minor changes. The regression problem has infinite possible output as the output is a real number. So, the model does not try to output the actual real number. Rather a predefined error is allowed, and the model tries to predict values that fall inside the predefined error range. The objective is to minimize the following:

The prediction of the model is represented as

$$
\frac{1}{2}\|w\|^{2}+C \sum_{i=1}^{N}\left(\varepsilon+\epsilon_{i}\right)
$$

$$
y=\sum_{i=1}^{N}\left(\alpha_{i}-\alpha_{i}^{*}\right) .<x_{i}, x>+b
$$

This model can capture the linear patterns of the data. For modeling the nonlinear feature in the data, which is the case with our historical temperature data, SVR applies a kernel function to convert the non-linear data into a linear representation in high dimensional space. This is commonly known as kernel trick. Some of the most common kernels are Linear, Polynomial, Radial Basis Function (RBF), and Sigmoid. With the introduction of the kernel, the output formula will change a bit to reflect the kernel applied to the input first.

$$
y=\sum_{i=1}^{N}\left(\alpha_{i}-\alpha_{i}^{*}\right) \cdot<\varphi\left(x_{i}\right), \varphi(x)>+b
$$

Here, $\varphi$ is the chosen kernel. The formula is represented in a simplified form as:

The kernel trick is illustrated in Figure 5:

$$
y=\sum_{i=1}^{N}\left(\alpha_{i}-\alpha_{i}^{*}\right) \cdot K\left(x_{i}, x\right)+b
$$

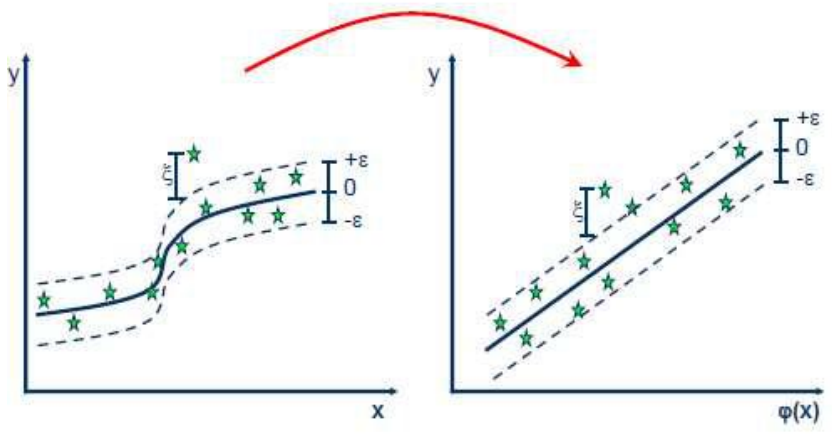

Figure 5: Kernel trick

Experiments are done with different kernels to model the temperature data.

Finally, the performance can be measured as Mean Absolute Error (MAE) or Mean Squared Error (MSE). In MSE the higher errors are penalized more than small errors. For this reason, MSE is considered as a standard measure to report the performance of this model. The MSE is formulated as:

$$
M S E=\frac{1}{N} \sum_{i=1}^{N}\left(y_{i}-\dot{y}_{i}\right)
$$

\subsection{Data Description}

In this study, the Berkeley Earth Surface Temperature dataset has been used (Rohde, 2013). The dataset is constructed from popular land and ocean temperature datasets called NOAA's MLOST, NASA's GISTEMP, and UK's HadCrut by Lawrence Berkeley National Laboratory. The dataset contains 1.6 billion temperature reports from 16 pre-existing archives. It contains data from 1750 in average format and 1850 with minimum and maximum temperature. In our model, data from 1900 have been used as there are no missing data points since then. In the dataset, temperature data is considered for only one point $(23.31 \mathrm{~N}, 90.00 \mathrm{E})$ in Bangladesh. This is a limitation of the study. With more points, the model will be able to predict temperature with more precision. 


\section{RESULTS AND DISCUSSION}

The results and findings of prediction model and the prediction of the temperature of Bangladesh in the next 100 years are analyzed in different sections.

\subsection{Incremental Trend in Mean Temperature}

The Table 1 summarizes the average temperature of the last 120 years separated into a 10 -year block. Each 10year block is the average of every year's temperature in that range. Averaging over 10 years normalize the oscillation in the temperature and shows a clear increase in the temperature of Bangladesh.

As it can be seen from the temperature data, on average there is around 1-degree temperature rise in the last century. So, the rise in this century is inevitable. There is also an upward trend in the minimum and the maximum temperature. Although it is not clear from the table, later it trains the models and fit it to the data to see the upward slope in the fitted curve to the data. Several models have been built to predict the temperature of Bangladesh in the next 100 years.

Table 1: Average temperature of Bangladesh in the past

\begin{tabular}{lccc}
\hline Year Range & $\begin{array}{c}\text { Mean } \\
\text { Temperature } \\
\left({ }^{0} \mathrm{C}\right)\end{array}$ & $\begin{array}{c}\text { Minimum } \\
\text { Temperature } \\
\left({ }^{0} \mathrm{C}\right)\end{array}$ & $\begin{array}{c}\text { Maximum } \\
\text { Temperature } \\
\left({ }^{0} \mathrm{C}\right)\end{array}$ \\
\hline $1900-1910$ & 24.53 & 16.78 & 28.57 \\
$1910-1920$ & 24.72 & 17.04 & 29.24 \\
$1920-1930$ & 24.86 & 16.62 & 29.23 \\
$1930-1940$ & 24.97 & 16.46 & 29.27 \\
$1940-1950$ & 25.01 & 17.49 & 29.58 \\
$1950-1960$ & 25.26 & 17.27 & 29.45 \\
$1960-1970$ & 25.14 & 17.16 & 29.64 \\
$1970-1980$ & 25.16 & 17.06 & 29.59 \\
$1980-1990$ & 25.29 & 17.39 & 29.79 \\
$1990-2000$ & 25.26 & 17.13 & 29.37 \\
$2000-2010$ & 25.53 & 17.23 & 29.71 \\
$2010-$ present & 25.61 & 17.28 & 29.87 \\
\hline
\end{tabular}

Figure 6 represents temperature data of the year 1900 to present has been plotted to find out the real-time scenario of increment in temperature of Bangladesh. Figure 6(a) portrays the Model on raw data. Figure 6(b) shows the model on the mean temperature of each year from which a clear upward trend of temperature rise can be seen. Figure 6(c) and 6(d) illustrate the Model on the minimum temperature of each year and Model on the maximum temperature of each year, respectively. Both graphs portray a zigzag trend of temperature, so these figures are not conclusive. Figure 6(e) shows every 10 year's mean which also illustrates an upward trend in temperature rise. These graphs are used to illustrate the fit of every model (linear regression model, polynomial regression model, and SVR) to the data to find out the best fit of the models.

\subsection{Performance of the Model}

The different models are used for prediction of the future temperature of Bangladesh. The linear model is the simplest model among them. Figure 7 shows the model fit to data. As we can see from the figure, it is hard to predict the raw behavior of the temperature with a linear regression model as there is too much fluctuation in the daily temperature. However, the linear regression model can capture the upwards trends of the mean, minimum, and maximum temperature although there is an error in the prediction. The model best fits the 10-year average data as there is less fluctuation in the data. It also done fairly well in mean temperature data but cannot capture the dumpy nature of minimum and maximum temperature.

Figure 8 shows that the polynomial regression does a much better fit to the temperature data compared to the linear regression model. This model can capture the complex pattern in the data and fit a curved line to make a close estimation of the data. But the temperature data is still not modeled well with the polynomial regression of degree 3 because the data has a higher dimensional feature than the polynomial regression can fit. Here, the model on the minimum and maximum temperature is better than the linear regression model. It is doing slightly better with the mean and 10-year average data too.

Illustrated in Figure 9, the SVM fits the complex pattern of the data far better than the Linear and Polynomial Regression modes. Especially the model with minimum and maximum temperature data makes a good fit to the data. 
(a) Raw Data

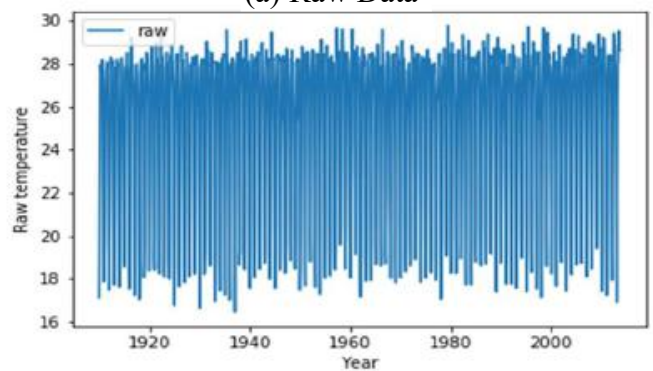

(b) Mean temperature

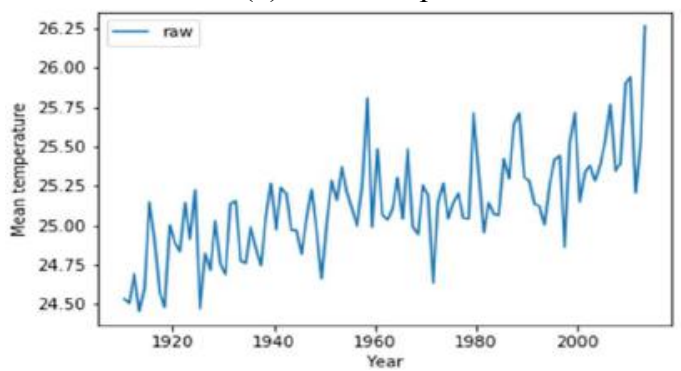

(c) Minimum temperature

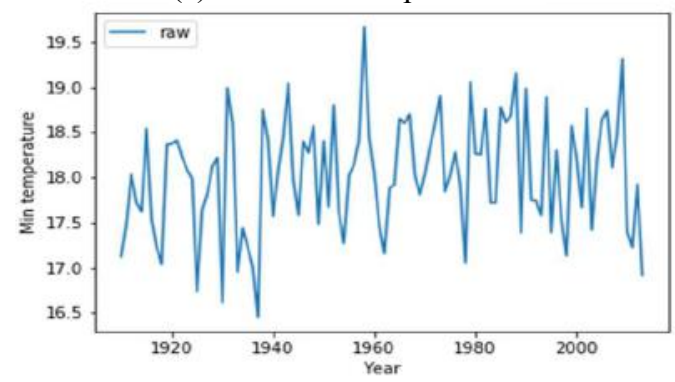

(d) Maximum temperature

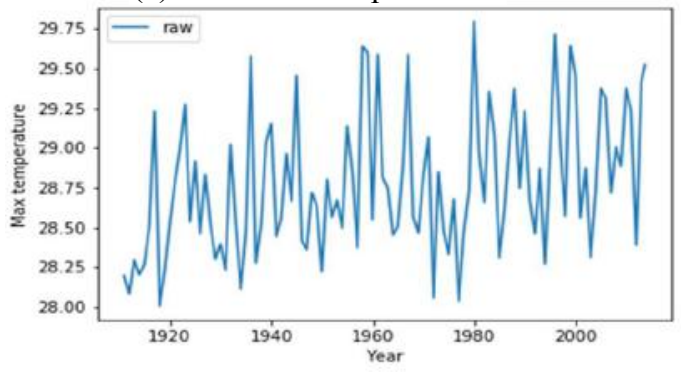

(e) 10-year average temperature

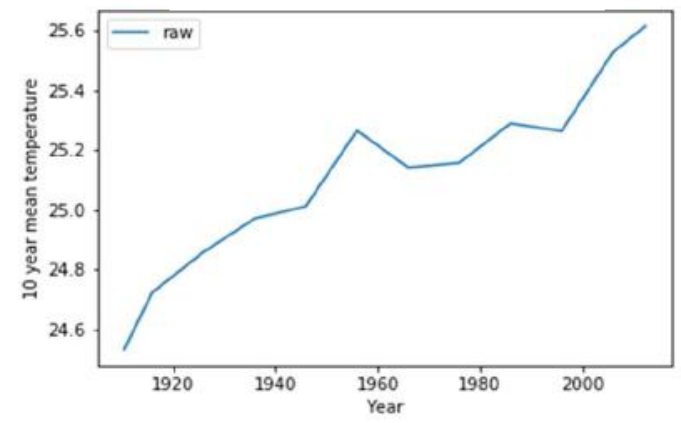

Figure 6: Temperature data distribution plot of the last century of Bangladesh (a) Model fit on Raw Data

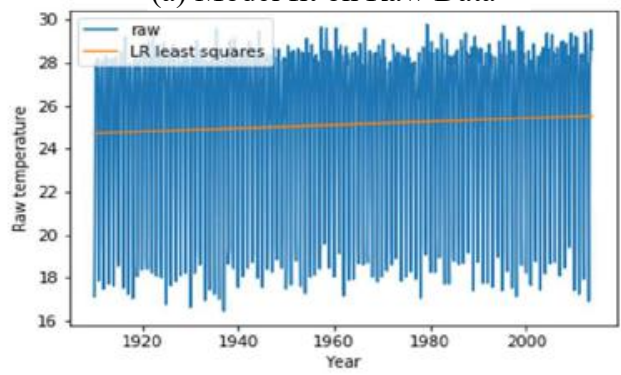

(b) Model fit on Mean temperature

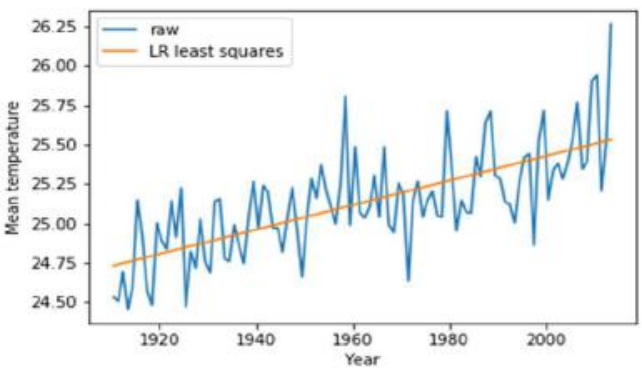

(c) Model fit on minimum temperature

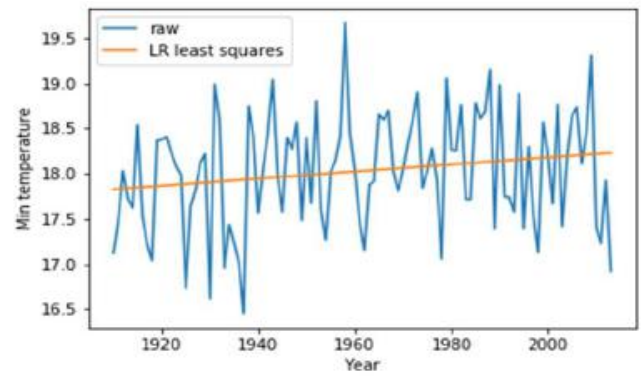

(d) Model fit on maximum temperature

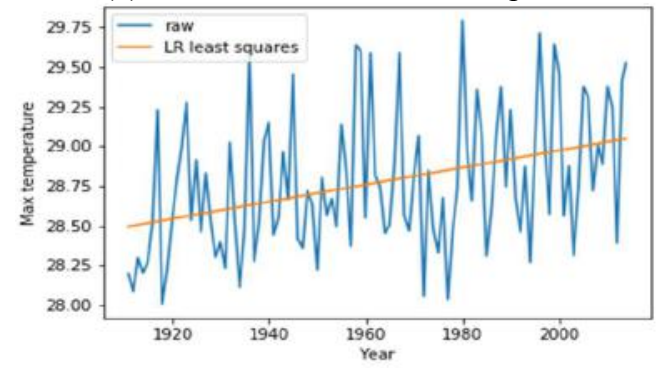

(e) Model fit on 10-year average temperature

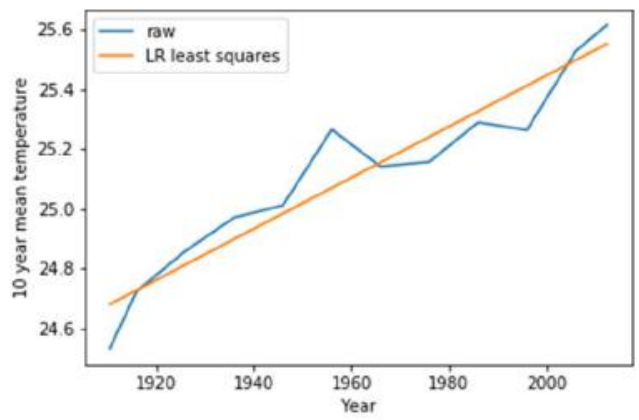

Figure 7: Linear Regression model fits on the temperature data 
(a) Model fit on Raw Data

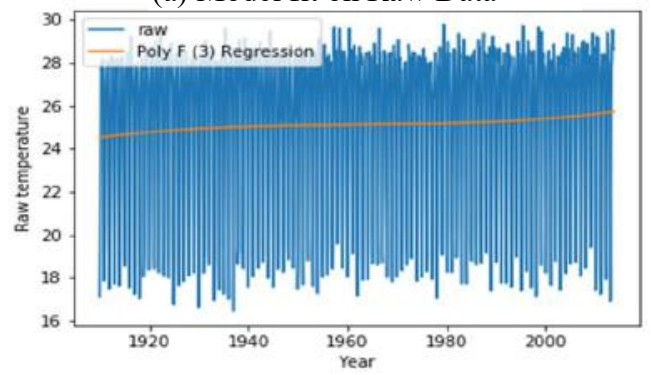

(b) Model fit on Mean temperature

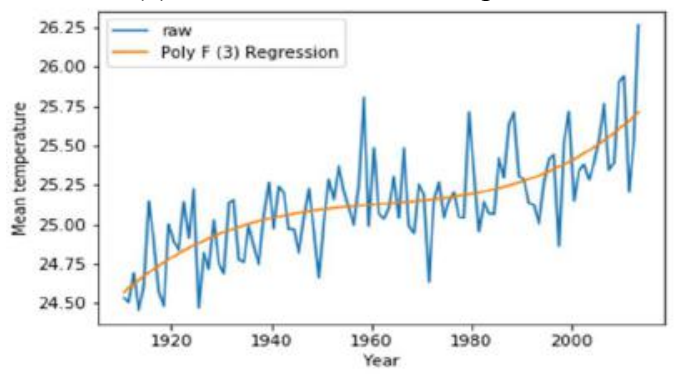

(c) Model fit on minimum temperature

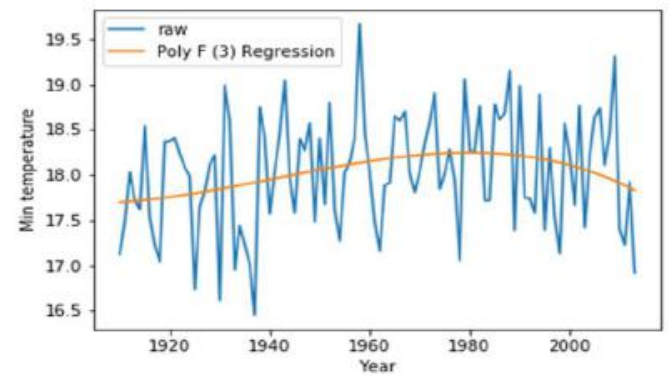

(d) Model fit on maximum temperature

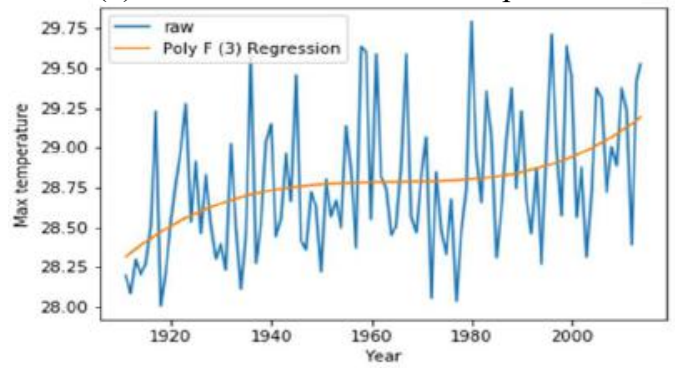

(e) Model fit on 10-year average temperature

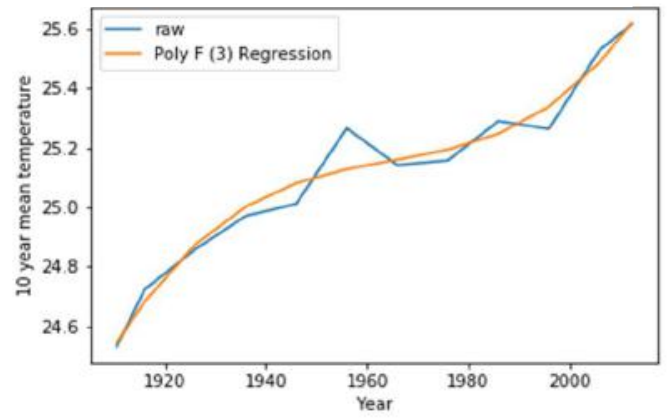

Figure 8: Polynomial Regression model of degree 3 fits on the temperature data (a) Model fit on Raw Data

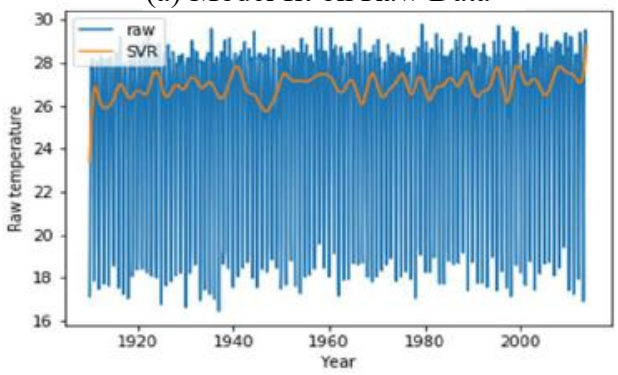

(b) Model fit on Mean temperature

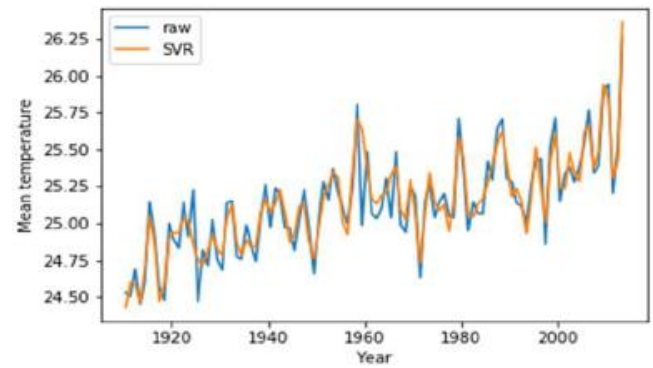

(c) Model fit on minimum temperature

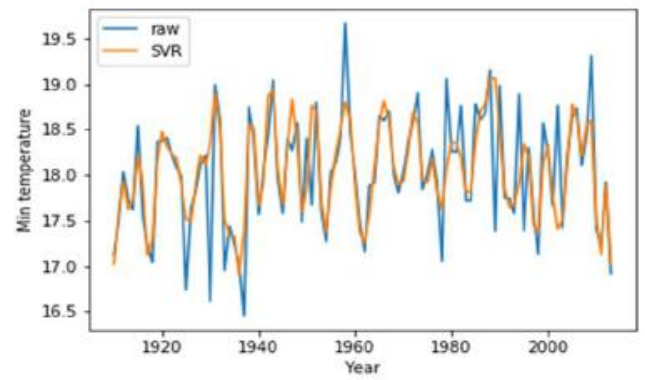

(d) Model fit on maximum temperature

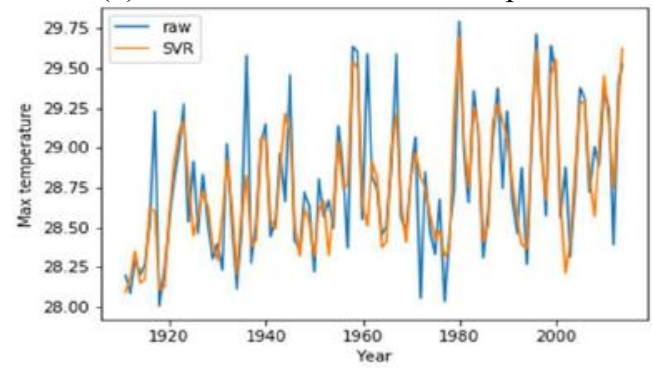

(e) Model fit on 10-year average temperature

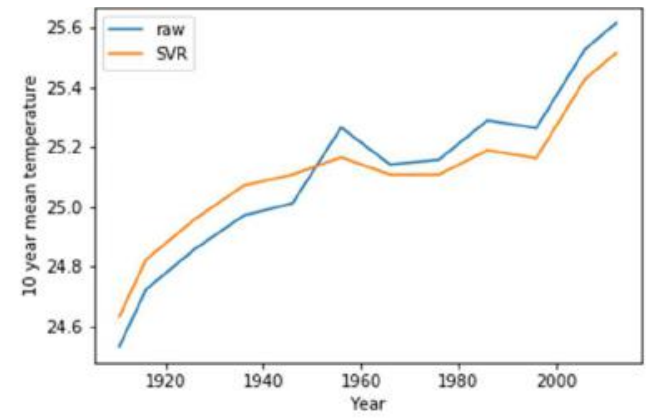

Figure 9: SVM model with RBF kernel fits on the temperature data 
Although the complex pattern has the chance of being over fitted by the model and might show unnecessary deviation in future prediction.

\subsection{Performance Comparison of Implemented Prediction Models}

The performance of the model depends on the error it makes compared to the original output. Lesser the error of the model better is that model. The model reports not only the raw data model but also modeled the mean, minimum, and maximum temperature of each year. We have also calculated a separate model for predicting the mean temperature of each decade. The table 2 summarizes the performance of the model on each data type by each model reported as MSE.

Table 2: Performance comparison of implemented prediction models in MSE

\begin{tabular}{lccccc}
\hline \multicolumn{1}{c}{ Model } & $\begin{array}{c}\text { Raw data } \\
\left({ }^{0} \mathrm{C}\right)\end{array}$ & $\begin{array}{c}\text { Average } \\
\text { of the year } \\
\left({ }^{0} \mathrm{C}\right)\end{array}$ & $\begin{array}{c}\text { Minimum } \\
\text { of the year } \\
\left({ }^{0} \mathrm{C}\right)\end{array}$ & $\begin{array}{c}\text { Maximum } \\
\text { of the year } \\
\left({ }^{0} \mathrm{C}\right)\end{array}$ & $\begin{array}{c}\text { 10-year } \\
\text { Average } \\
\left({ }^{\circ} \mathrm{C}\right)\end{array}$ \\
\hline Linear regression & 14.15 & 0.0566 & 0.0566 & 0.3879 & 0.1663 \\
Polynomial regression (degree=3) & 0.0054 & 0.0047 & 0.0174 & 0.0043 & 0.0054 \\
Polynomial regression (degree=5) & 0.0055 & 0.0048 & 0.0175 & 0.0044 & 0.0055 \\
SVR (kernel = RBF) & 3.4509 & 0.0465 & 0.2603 & 0.1202 & 0.0161 \\
SVR (kernel = Polynomial) & 1.2473 & 0.4396 & 2.1434 & 1.0272 & 0.5565 \\
\hline
\end{tabular}

As it can be seen from the model that the Polynomial Regression has better performance in terms of MSE compared with other models. The significance of each of the numbers is that the average error of a predicted temperature at a given time from its actual temperature is the root of the reported number in this table. For example, the MSE of the average temperature model with the polynomial regression of degree 5 is 0.0048 . The root is 0.069 . That means if the predicted temperature is $25.00^{\circ} \mathrm{C}$. The actual temperature lies between 24.93 to $25.069^{\circ} \mathrm{C}$, which is a minor difference and can be considered as the near-perfect prediction.

As table 2 shows, for predicting all the variations of raw, mean, minimum, maximum, and 10-year average temperature Polynomial regression with degree 3 has the lowest prediction error. SVR with polynomial kernel has a high MSE error in almost all prediction except for the linear regression model has the highest error in raw data prediction. So, the polynomial model with degree 3 can be considered as the best model for predicting the future temperature of Bangladesh. From now onward, all the performances are reported with this model.

\subsection{Temperature prediction from the model}

As it has been found that Polynomial Regression model has better performance among the three models, the temperature of Bangladesh for the next 100 years has been predicted using this model. Table 3 gives the predicted average temperature of Bangladesh.

Table 3: Predicted average temperature of Bangladesh in the next 100 years

\begin{tabular}{ccccc}
\hline Year & $\begin{array}{c}\text { Average } \\
\text { Temperature }\left({ }^{0} \mathrm{C}\right)\end{array}$ & & Year & $\begin{array}{c}\text { Average } \\
\text { Temperature }\left({ }^{0} \mathrm{C}\right)\end{array}$ \\
\cline { 1 - 2 } \cline { 5 - 5 } 2025 & 25.62 & & 2075 & 26.01 \\
2030 & 25.66 & & 2080 & 26.05 \\
2035 & 25.7 & & 2085 & 26.09 \\
2040 & 25.74 & & 2090 & 26.13 \\
2045 & 25.78 & & 2095 & 26.17 \\
2050 & 25.82 & & 2100 & 26.2 \\
2055 & 25.85 & & 2105 & 26.24 \\
2060 & 25.89 & & 2110 & 26.28 \\
2065 & 25.93 & & 2115 & 26.32 \\
2070 & 25.97 & & 2120 & 26.36 \\
\hline
\end{tabular}

As we can see from the table 2 there is a predicted increment in temperature from 25.62 to $26.36^{\circ} \mathrm{C}$, which is close to $1^{\circ} \mathrm{C}$ increment in one century. Apart from the success of the model in predicting the average temperature of each year, there are some limitations in this research. The seasonal temperature variation is not analyzed in our word and month-wise temperature prediction is not possible with our model.

\section{CONCLUSIONS}

In this study, the past 100 years temperature data of Bangladesh has been analyzed and it has been seen that in the past 100 years temperature of Bangladesh has risen by $1^{0} \mathrm{C}$ on average. Linear regression model, polynomial 
regression model and SVR are developed to predict the average temperature of each year in Bangladesh for the next 100 years. The performances of those models are compared, and it is found that the polynomial regression

with degree 3 is the best model for this application. An increase of close to another $1^{0} \mathrm{C}$ can be seen in the average temperature of Bangladesh from the prediction of the model.

\section{REFERENCE}

A1, S.E.T., 2006. Observational Constraints on Past Attributable Warming and Predictions of Future, 19(13), 3055-3069, https://doi.org/10.1175/JCLI3802.1

Alley, R.B., Hewitson B., Hoskins B.J., Joos F., Jouzel J., Kattsov V., Lohmann U., Manning M., Matsuno T., Molina M., Nicholls N., Berntsen T., Overpeck J., Qin D., Raga G., Ramaswamy V., Ren J., Rusticucci M., Solomon S., Somerville R., Stocker T.F., Stott P.A., Bindoff N.L., Stouffer R.J., Whetton P., Wood R.A., Wratt D., Chen Z., Chidthaisong A., Friedlingstein P., Gregory J.M., Hegerl G.C., and Heimann M., 2007. Summary for policymakers, in S Solomon and D Qin and M Manning and M Marquis and KB Averyt and M Tignor and HL Miller and Z Chen (eds.), Climate Change 2007: The Physical Science Basis. Contribution of Working Group 1 to the Fourth Assessment Report of the Intergovernmental Panel on Climate Change (pp. 1-18). Cambridge, UK and NY, USA: Cambridge University Press.

Daily Star, 2019. Human ecology, changing climate and hydrology, Retreived from Daily Star: http://www.thedailystar.net/newDesign/news- details.php?nid=209731.

Daily Star, 2019. Vulnerable women, children need special attention, Retreived from Daily Star:http://www.the dailystar.net/newDesign/news-details.php?nid=208648.

Drucker, H., Burges C.J., Kaufman L., Smola A.J., and Vapnik V., 1997. Support vector regression machines, In Advances in neural information processing systems, 28(7), 155-161.

Elahi, F., and Khan N.I., 2015. A Study on the effects of global warming in Bangladesh, International Journal of Environmental Monitoring and Analysis, 3(3), 118-122.

Fyfe, J.C., Merryfield W.J., Kharin V., Boer G.J., and Lee W.S., 2011. Skillful predictions of decadal trends in global mean surface temperature, Geophys, Res. Lett, 38, p.L22801.

Houghton, J., 2004. Global Warming: The Complete Briefing (Third Edition), Cambridge University Press, 86(30), 282-283.

ICDDR, B., 2019. Our Strategy, Retrieved from icddr, b: https://www.icddrb.org/about-us/strategy

Islam, S.S., 2004. Status of forest genetic resources conservation and management in Bangladesh. In Forest Genetic Resources Conservation and Management: Proceedings of the Asia Pacific Forest Genetic Resources Programme (APFORGEN) Inception Workshop, Kepong, Kuala Lumpur, Malaysia, 15-18 July 2003 (p. 27), Biodiversity International.

Lindzen, R. S., 2008. Global Warming: What Is It All About?, Retrieved from EPA:https://www.epa.gov/ environmental-economics/global-warming-what-it-all-about

Mahmood, S.A.I., 2012. Impact of Climate Change in Bangladesh: The Role of Public Administration and Government's Integrity, Journal of Ecology and the Natural Environment, 4(8), 223-240, https://doi.org/ $10.5897 /$ jene 11.088

Orr, G., 2007. Global warming [1], Structural Engineer, 85(17), 34.

Pender, J.S., 2008. What is climate change? and how it will affect Bangladesh, Briefing paper (final draft). Dhaka, Bangladesh: Church of Bangladesh Social Development Programme.

Rohde, R., Muller R., Jacobsen R., Perlmutter S., Rosenfeld A., Wurtele J., Curry J., Wickhams C., and Mosher S., 2013. Berkeley Earth Temperature Averaging Process, Geoinfor, Geostat.: An Overview \$1: $2 \$$. Geoinformatics Geostatistics An Overview, 1(2), 20-100.

Ruppert, D., 1997. Local polynomial regression and its applications in environmental statistics, Statistics for the Environment, 3, 155-173.

Shahzad, U., 2015. Global Warming: Causes, Effects and Solutions, Durreesamin Journal, 1(4), 1-7.

Smith, D. M., Scaife A. A., Boer G. J., Caian M., Doblas-Reyes F. J., Guemas V., Hawkins E., Hazeleger W., Hermanson L., Ho C. K., Ishii M., Kharin V., Kimoto M., Kirtman B., Lean J., Matei D., Merryfield W. J., Müller W. A., Pohlmann H., ... Wyser K., 2013. Real-time multi-model decadal climate predictions, Climate Dynamics, 41(11-12), 2875-2888, https://doi.org/10.1007/s00382-012-1600-0

Tol, R.S., 2006. The Stern review of the economics of climate change: a comment, Energy \& Environment, 17(6), 977-981.

UNFCCC, 2005. Depledge, J., and Lamb R., eds., Caring for Climate: A guide to the Climate Change Convention and the Kyoto Protocol (pp. 1-33). Bonn, Germany: Climate Change Secretariat (UNFCCC).

Venkataramanan, M., 2011. Causes and effects of global warming, Indian Journal of Science and Technology, 4(3), 226-229.

Zholudeva, V. V., 2019. Statistical assessment of the impact of climate change on social and demographic processes (on the example of the Yaroslavl region), Statistics and Economics, 16(6), 57-66. 